\title{
Spectral Analysis of Polystyrene, Polypropylene, and Poly(methyl methacrylate) Polymers in TOF SIMS and XPS by MO Calculations Using the Model Oligomers
}

\author{
Kazunaka Endo, ${ }^{\dagger}$ Naoya KoBAYASHI, Masayuki AidA, \\ and Takahiro HosHI* \\ Tsukuba Research Laboratory, Mitsubishi Paper Mills, Ltd., \\ 46 Wadai Tsukuba-shi, Ibaraki 300-42, Japan \\ * Analytical Laboratory, Ulvac-phi Inc., 2500 Hagisono, Chigasaki 253, Japan
}

(Received April 5, 1996)

\begin{abstract}
Spectra of the polystyrene (PS), polypropylene (PP), and poly(methyl methacrylate) (PMMA) polymers in time-of-flight secondary ion mass spectrometry (TOF SIMS) and valence X-ray photoelectron spectroscopy were analyzed by the MO calculations using the model oligomers. For TOF SIMS, we tried to predict where the scission of polymers can occur on sputtering, due to bond-orders of the model 5- or 3-mers by a semiempirical MO calculations. We also determined the probable structural formulas of the secondary positive-ion fragments in the range of $0-100$ amu by ab initio MO calculations using HONDO7 program. The valence X-ray photoelectron spectra (XPS) of the polymers were simulated by a semiempirical HAM/3 MO method using the trimer model molecules. The theoretical spectra showed good agreement with the observed spectra of polymers between $0-40 \mathrm{eV}$.

KEY WORDS Time-of-Flight Secondary Ion Mass Spectroscopy (TOF SIMS) / Valence X-Ray Photoelectron Spectra (XPS) / Ab Initio and Semiempirical MOs / Positive Secondary Ions / Bond-Order / Polymer / Polystyrene / Polypropylene / Poly(methyl methacrylate) /
\end{abstract}

Time-of-flight secondary ion mass spectrometry (TOF SIMS) and X-ray photoelectron spectroscopy have become powerful tools for studying polymer surface. Informations $^{1-5}$ obtained from TOF SIMS included monomer molecular weight, fragmentation pathways, molecular weight distribution of oligomers and spectra characteristic of a specific polymer family. On the other hand, there has been no study about spectral analysis of polymers in SIMS by MO calculations, since the emission process of secondary ions, atoms or molecules on sputtering will be very complicated. In the present study, our aim is to predict where the scission of (polypropylene (PP), polystyrene (PS), and poly(methyl methacrylate) (PMMA)) polymers can occur on sputtering, due to bond-orders of the model 5- or 3-mers from semiempirical MO calculations using AM1 program. ${ }^{6}$ We also aim to determine the probable structural formulas of the secondary positive-ions by $a b$ initio MO calculations using HONDO7 program. ${ }^{7}$ Experimentally, we obtained the different spectra of the stereoisomer (atactic and isotactic) PMMA in the range of 800-1200 amu in TOF SIMS, as obtained by Zimmerman and Hercules. ${ }^{8}$

Some X-ray photoelectron spectra (XPS) studies $^{9-13}$ of model oligomers and saturated hydrocarbons demonstrated that information on the conformation and tacticity dependence can be obtained through spectral simulation by MO calculations. Delhalle et al. ${ }^{13}$ found evidence of folded structure at the surface of polyethylene lamellae in the XPS valence band. In our previous papers, ${ }^{14-20}$ we used syndiotactic model molecules for analysis of XPS of polymers, because we found that the tacticity had little effect on the calculated energy structures, in contradiction to the results of other workers. ${ }^{12,13}$ For better assignment ${ }^{18-20}$ of valence XPS

\footnotetext{
$\dagger$ To whom correspondence should be addressed
}

of polymers involving carbon, nitrogen, oxygen, and fluorine, we tested the performance of semiempirical hydrogenic atoms in molecule, version $3(\mathrm{HAM} / 3) \mathrm{MO}$ method $^{21-23}$ in that the results can be directly compared with experiment, because it uses the idea of transition states $^{24}$ rather than Koopmans' theorem to predict vertical ionization potentials (VIPs).

The present paper also offers observed and simulated spectra in X-ray photoelectron spectroscopy for atactic and isotactic PP, PS, and PMMA polymers. We found a little difference of atactic and isotactic PMMA between observed spectra at around $14 \mathrm{eV}$. The difference of the tacticity in valence XPS was unable to be explained by the theoretical result by $\mathrm{HAM} / 3 \mathrm{MO}$ calculations using the model molecules. The simulation of valence XPS was performed for trimer models using the standard convolution techniques by a Gaussian lineshape and using the Gelius model ${ }^{25}$ for molecular photoionization crosssection.

\section{MO CALCULATIONS}

\section{Simulation of Valence XPS}

The electronic structure of model trimers $\left[\mathrm{H}-\left(\mathrm{CH}_{2}-\right.\right.$ $\left.\mathrm{C}\left(\mathrm{CH}_{3}\right) \mathrm{COOCH}_{3}\right)_{3}-\mathrm{H}, \mathrm{H}-\left(\mathrm{CH}_{2}-\mathrm{CH}\left(\mathrm{CH}_{3}\right)\right)_{3}-\mathrm{H}$, and $\left.\mathrm{H}-\left(\mathrm{CH}_{2}-\mathrm{CH}\left(\mathrm{C}_{6} \mathrm{H}_{5}\right)\right)_{3}-\mathrm{H}\right]$ for isotactic, syndiotactic, and heterotactic types were calculated using a new version of HAM/3 program extended by Chong. ${ }^{26}$ For the geometry of the molecules, we used the optimized cartesian coordinates from the semi-empirical AM1 (version 6.0) method.

In the $\mathrm{HAM} / 3$ program, we can obtain the three sets of relative atomic photoionization cross-section as permanent data: (a) Gelius empirical parameters for $\mathrm{Mg}-K_{\alpha}(1253.6 \mathrm{eV})$ radiation, (b) theoretical values from Nefedov et al. ${ }^{27}$ for $\mathrm{Mg}-K_{\alpha}$ radiation, and (c) theoretical 
values from Nefedov et al. for $\mathrm{Al}-K_{\alpha}(1486.6 \mathrm{eV})$ radiation. In this paper, we report the results from set (c) only, because of $\mathrm{Al}-K_{\alpha}$ radiation was used in the present experiment. In order to simulate the valence XPS of polymers theoretically, we constructed from a superposition of peaks centered on the VIPs, $I_{k}$. As was done in previous works, ${ }^{18-20}$ each peak was represented by a Gaussian lineshape function. The intensity is estimated from the relative photoionization cross-section for $\mathrm{Al}-K_{\alpha}$ radiation using the Gelius intensity model. In the case of linewidth $(W H(k))$, we used $W H(k)=0.10 I_{\mathrm{k}}$ for the models, as adopted in previous works. ${ }^{18-20}$

\section{Bond-orders of Model Oligomers and Fragment Ions for Mass Spectral Analysis in SIMS}

The electronic structure of model oligomers $\left[\mathrm{H}-\left(\mathrm{CH}_{2}-\right.\right.$ $\left.\mathrm{C}\left(\mathrm{CH}_{3}\right) \mathrm{COOCH}_{3}\right)_{3}-\mathrm{H}, \mathrm{H}-\left(\mathrm{CH}_{2}-\mathrm{CH}\left(\mathrm{CH}_{3}\right)\right)_{5}-\mathrm{H}$, and $\left.\mathrm{H}-\left(\mathrm{CH}_{2}-\mathrm{CH}\left(\mathrm{C}_{6} \mathrm{H}_{5}\right)\right)_{3}-\mathrm{H}\right]$ were calculated using a semiempirical AM1 program (version 6.0). Figure 1 shows the bond-orders of the model oligomers of PP, PMMA, and PS polymers for the optimized results, as obtained by the energy gradient method.

The electronic structure of the fragment positive-ions for three polymers were obtained by $a b$ initio calculations using a HONDO7 program. For the geometry of the fragment positive ions, we used optimized cartesian coordinates from the AM1 program. In the $a b$ initio calculations, we used a restricted Hartree-Fock (RHF)/4-
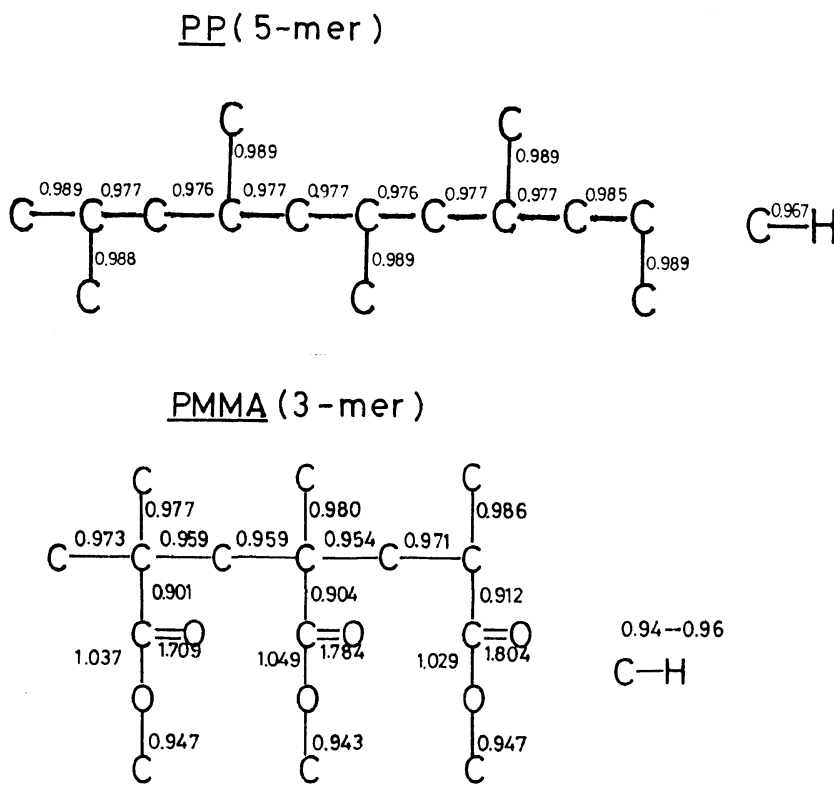

\section{PS (3-mer)}

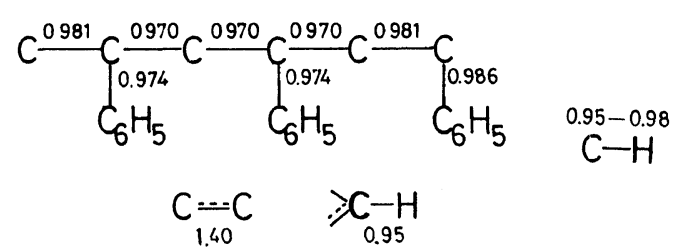

Figure 1. Bond-orders of the model oligomers $\left[\mathrm{H}-\left(\mathrm{CH}_{2}-\mathrm{CH}-\right.\right.$ $\left.\left(\mathrm{CH}_{3}\right)\right)_{5}-\mathrm{H}, \mathrm{H}-\left(\mathrm{CH}_{2}-\mathrm{C}\left(\mathrm{CH}_{3}\right) \mathrm{COOCH}_{3}\right)_{3}-\mathrm{H}$ and $\mathrm{H}-\left(\mathrm{CH}_{2}-\mathrm{CH}-\right.$ $\left.\left.\left(\mathrm{C}_{6} \mathrm{H}_{5}\right)\right)_{3}-\mathrm{H}\right]$ for PP, PMMA, and PS polymers, respectively, as calculated using a semiempirical AM1 program.
$31 \mathrm{G}$ basis set for $\mathrm{H}, \mathrm{C}$, and $\mathrm{O}$ atoms without electroncorrelation.

\section{EXPERIMENTAL}

\section{Materials}

We used commercially-available polypropylene (PP) (Scientific Polymer Products, Inc.; atactic and isotactic types), poly(methyl methacrylate) (PMMA) (Aldrich Chemical Co., Inc.; atactic type $M_{w} 93300$ and isotactic type $M_{w} 300000$ ), and polystyrene (PS) (Scientific Polymer Products, Inc.; atactic type $M_{w} 280000$ and isotactic type $M_{w}$ 400000).

Samples for XPS measurements were prepared by cast-coating the polymer solution on an aluminium plate, while toluene and chloroform were used for (PP, isotactic PMMA and isotactic PS) and (atactic PMMA and atactic PS) polymers, respectively. The film was estimated to be a few tens of micrometers thick.

In the TOF SIMS measurement to obtain the different spectra of the stereoisomers (isotactic and atactic polymers), solutions of $1 \mathrm{~g} \mathrm{~L}^{-1}$ of the polymers were produced, from which 1 to $5 \mu \mathrm{L}$ of the solutions was deposited on the silver foils. The procedure resulted in the deposition of a monolayer or less on the silver surface.

\section{XPS Measurements}

The experimental photoelectron spectra of the polymers were obtained on a PHI 5400 MC ESCA spectrometer, using monochromatized $\mathrm{Al}-\mathrm{K}_{\alpha}$ radiation. The spectrometer was operated at $600 \mathrm{~W}, 15 \mathrm{kV}$, and $40 \mathrm{~mA}$. The photon energy was $1486.6 \mathrm{eV}$. A pass energy of $35.75 \mathrm{eV}$ was employed for high-resolution scans in a valence-band analysis ( $50 \mathrm{eV}$ of range). The angle between the X-ray source and the analyzer was fixed at $45^{\circ}$. The spot size in the measurement was $3 \times 1 \mathrm{~mm}$.

The use of dispersion compensation yielded an instrumental resolution of $0.5 \mathrm{eV}$ with the full width at half-maximum on the Ag3d line of silver. Multiple-scan averaging on a multi-channel analyzer was used for the valence-band region, although a very low photoelectron emission cross section was observed in this range.

Gold of $20 \AA$ thick was deposited on the films of the polymer samples using an ion sputter unit (Hitachi $\mathrm{E}$ 1030) for scanning microscope. A low-energy electron flood gun was used in order to avoid any charging effect on the surface of the sample. We used the Au4f core level of the gold decoration films as a calibration reference. The $\mathrm{Cls}$ line positions of $\mathrm{CH}_{2}$ groups on the polymer films could be fixed at 285.0 and 285.2 for (PP, PS) and PMMA, respectively.

\section{TOF SIMS Measurements}

We operated a PHI TOF SIMS TFS-2000 spectrometer with a primary $\mathrm{Ga}^{+}$ion beam $\left(12 \mathrm{keV} \mathrm{Ga}^{+}\right.$, pulse with $13 \mathrm{~ns}$, repetition rate $10 \mathrm{kHz}$, a primary ion current of $700-800 \mathrm{pA}$ measured as a continuous beam). The generated secondary ions are accelerated to $3 \mathrm{keV}$. The intensity changes of the given ion species during the irradiation of the primary ion beam (denoted as dose profiles) were evaluated through an ion dosage up to $2.5 \times 10^{12}$ ions per $\mathrm{cm}^{2}$. A new charge compensation system, based on a low-energy electron source $(10 \mathrm{eV})$ 
and a pulsed extraction field of the mass analyzer, provides a self-adjusting surface potential for all kinds of insulators in the positive and negative SIMS mode. In the present work, we used the positive mode.

\section{RESULTS AND DISCUSSION}

\section{Analysis of Valence XPS of the Polymers}

In the previous paper, ${ }^{18}$ a new approach was tested by comparing the valence XPS of polypropylene with $\mathrm{HAM} / 3$ results on the syndiotactic model molecules, $\mathrm{H}-\left(\mathrm{CH}_{2}-\mathrm{CH}\left(\mathrm{CH}_{3}\right)\right)_{n}-\mathrm{H}$, for $n=2$ to 5 . The results

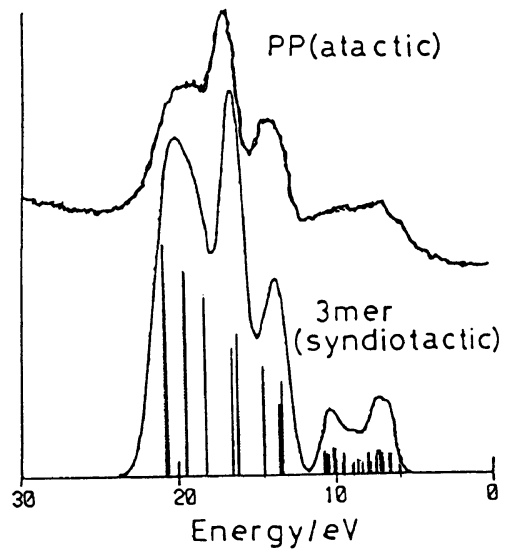

(a)

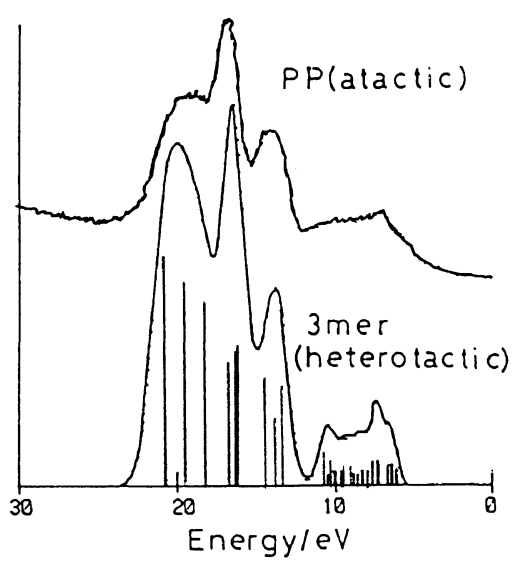

(b)

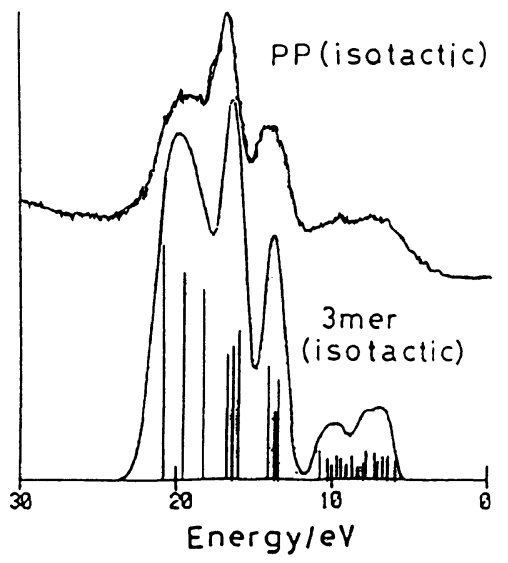

(c)

Figure 2. Valence XPS of atactic PP with the simulated spectrum of (a) the syndiotactic and (b) heterotactic trimer model molecule as calculated using HAM/3. (c): Valence XPS of isotactic PP with the simulated spectrum of the isotactic trimer model using $\mathrm{HAM} / 3$. suggested that the trimer model is quite adequate in simulating valence XPS of solid polymers, when we introduced a shift WD to account for a sum of the work function and other energy effects. In Figures 2(a)-(c), we observed similar spectra in the range of $0-30 \mathrm{eV}$ for commercially available atactic PP and isotactic PP, respectively. Computationally, we obtained similar simulated spectra with the spectral patterns for three stereoisomers of PP, using the model trimer molecules (Figures 2(a)-(c)). The results accorded well with the observed spectra, and seem to correspond to the zig-zag conformation. We omitted the table for observed peaks, calculated VIPs and orbital nature of the PP, as given in previous work. ${ }^{18}$

We, thus, conclude that the valence XPS of PP is too insensitive to distinguish the stereoisomer. This finding disagreed with the results of conformational dependency of PP using the parametric extended Huckel crystal orbital (EHCO) method. ${ }^{12}$ This disagreement may be due to the difference between the stereoisomers which we considered, and the zig-zag planar- or helicalconformations which Delhalle used, and the other difference between the $\mathrm{HAM} / 3$ and the EHCO MO methods.

For isotactic and atactic PMMA polymers, we obtained the high resolution valence-band spectra in the range of $0-30 \mathrm{eV}$ with twice longer acquisition times

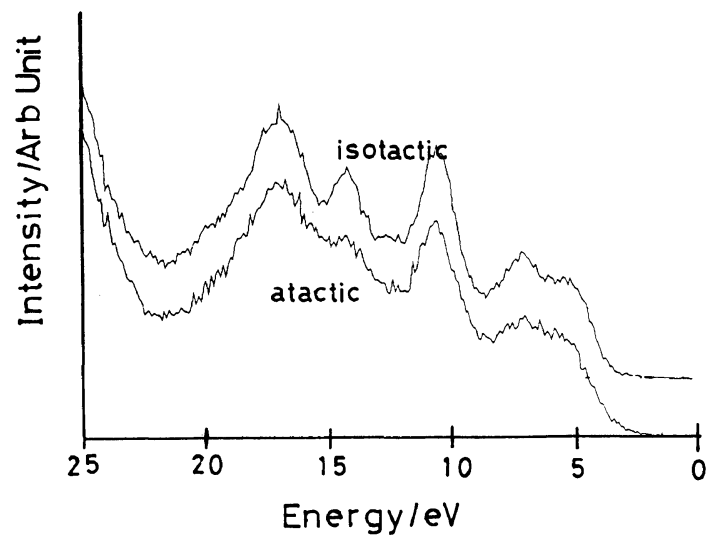

(a)

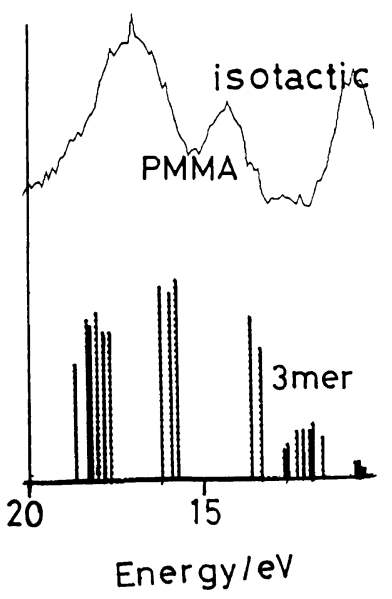

(b)

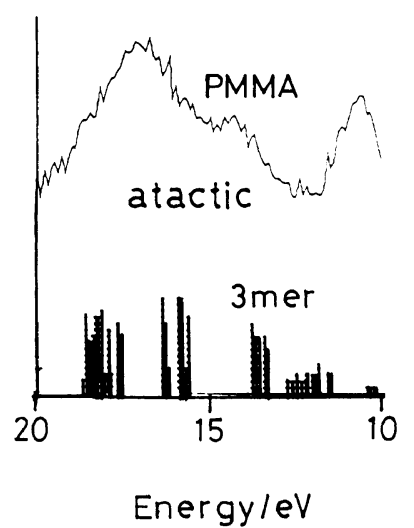

(c)
Figure 3. (a): Valence XPS of isotactic and atactic PMMA in the range of $0-25 \mathrm{eV}$. (b): Valence XPS of isotactic PMMA with spectral patterns of the isotactic trimer model using $\mathrm{HAM} / 3$ in the range of $10-20 \mathrm{eV}$. (c): Valence XPS of atactic PMMA with spectral patterns of the atactic trimer model using $\mathrm{HAM} / 3$ in the range of $10-20 \mathrm{eV}$. 
than with the normal scanning time ( $30-40$ minutes) in the range of $0-50 \mathrm{eV}$. Figure 3 (a) shows the observed valence-band spectra between 0 and $25 \mathrm{eV}$. In the figure, we can see the different peaks at around $14 \mathrm{eV}$ between

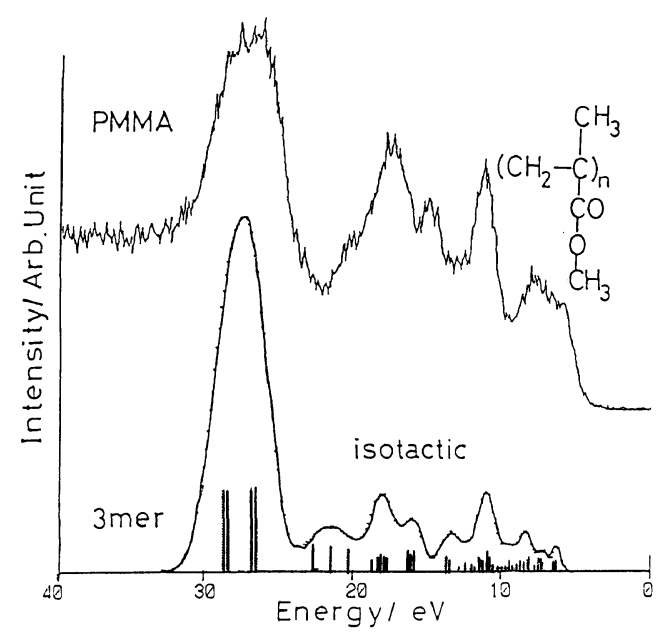

(a)

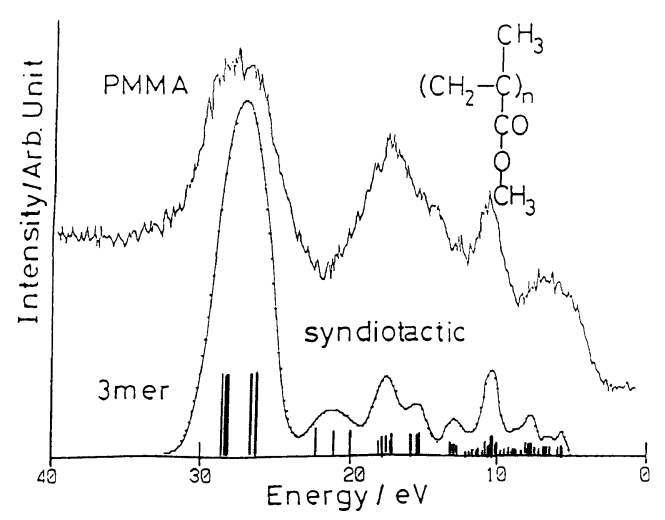

(b)

Figure 4. (a): Valence XPS of isotactic PMMA with the simulated spectrum of the isotactic trimer model using HAM/3. (b): Valence XPS of atactic PMMA with the simulated spectrum of the syndiotactic trimer model using $\mathrm{HAM} / 3$. both types. In order to simulate the spectra in the range of $10-20 \mathrm{eV}$, the theoretical patterns for the atactic type were derived by considering the probability for the existence of the three stereoisomers. The probability was determined from the ${ }^{1} \mathrm{H}$ NMR spectra as $1.00,0.77$, and

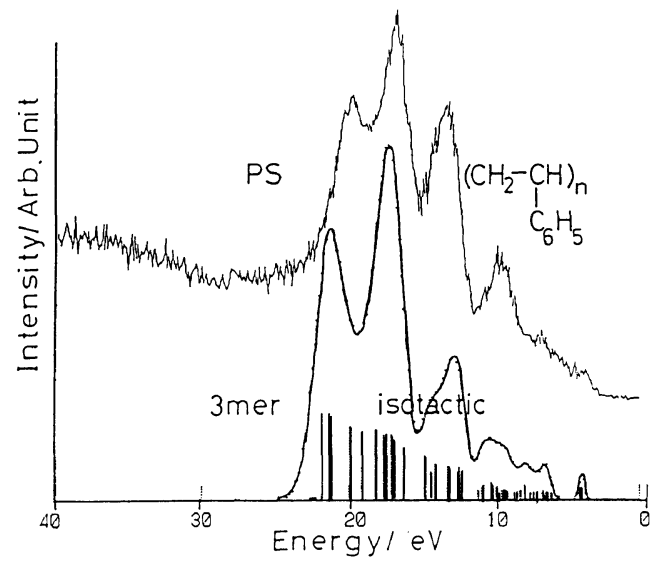

(a)

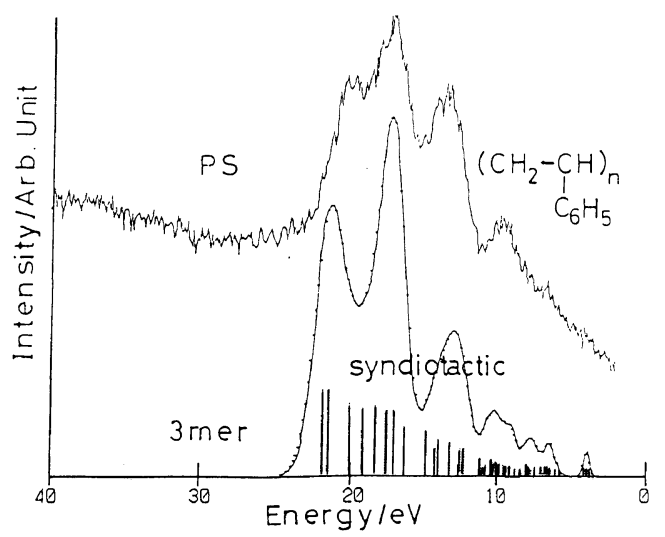

(b)

Figure 5. (a): Valence XPS of isotactic PS with the simulated spectrum of the isotactic trimer model using HAM/3. (b): Valence XPS of atactic PS with the simulated spectrum of the syndiotactic trimer model using $\mathrm{HAM} / 3$.

Table I. Observed peaks, VIP, main AO PICS, orbital nature, and functional group for valence XPS of PS $[($ the gap between observed and calculated VIPs) $=5.0 \mathrm{eV}]$

\begin{tabular}{|c|c|c|c|c|}
\hline Peak/eV & $\mathrm{VIP} / \mathrm{eV}$ & Main AO PICS & Orbital nature ${ }^{\mathbf{b}}$ & Functional group \\
\hline $\begin{array}{c}20.0 \\
(19-23)^{\mathrm{a}}\end{array}$ & $\begin{array}{l}(26.81 ; 26.44 ; 26.30) \\
\quad(24.92 ; 24.07)\end{array}$ & $\begin{array}{l}\mathrm{C} 2 \mathrm{~s} \\
\mathrm{C} 2 \mathrm{~s}\end{array}$ & $\begin{array}{l}\mathrm{s} \sigma(\mathrm{C} 2 \mathrm{~s}-2 \mathrm{~s})-\mathrm{B} \\
\mathrm{s} \sigma(\mathrm{C} 2 \mathrm{~s}-2 \mathrm{~s})-\mathrm{B}\end{array}$ & $\begin{array}{l}-\mathrm{C}_{6} \mathrm{H}_{5},-\mathrm{C} \text { (main chain) } \\
-\mathrm{C} \text { (main chain), }-\mathrm{C}_{2} \mathrm{H}_{5}\end{array}$ \\
\hline $\begin{array}{c}17.0 \\
(15.5-19)^{\mathrm{a}}\end{array}$ & $\begin{array}{l}(23.18 ; 22.55 ; 22.48 ; \\
\quad 22.42 ; 22.04) \\
(21.89 ; 21.31)\end{array}$ & $\begin{array}{l}\mathrm{C} 2 \mathrm{~s} \\
\mathrm{C} 2 \mathrm{~s}\end{array}$ & $\begin{array}{l}\mathrm{s} \sigma(\mathrm{C} 2 \mathrm{~s}-2 \mathrm{~s})-\mathrm{B} \\
\mathrm{s} \sigma(\mathrm{C} 2 \mathrm{~s}-2 \mathrm{~s})-\mathrm{B}\end{array}$ & $\begin{array}{l}-\mathrm{C}_{6} \mathrm{H}_{5} \\
-\mathrm{C} \text { (main chain), }-\mathrm{C}_{6} \mathrm{H}_{5}\end{array}$ \\
\hline $\begin{array}{c}13.5 \\
(12-15.5)^{\mathrm{a}}\end{array}$ & $\begin{array}{r}(19.80 ; 19.13 ; 18.94 ; \\
18.27 ; 18.15 ; 18.12) \\
(17.52 ; 17.28 ; 17.22)\end{array}$ & $\begin{array}{l}\mathrm{C} 2 \mathrm{~s} \\
\mathrm{C} 2 \mathrm{~s} \\
\mathrm{C} 2 \mathrm{~s}\end{array}$ & $\begin{array}{l}\mathrm{s} \sigma(\mathrm{C} 2 \mathrm{~s}-2 \mathrm{~s})-\mathrm{B} \\
\mathrm{p} \sigma(\mathrm{C} 2 \mathrm{~s}-2 \mathrm{p})-\mathrm{B} \\
\mathrm{p} \sigma(\mathrm{C} 2 \mathrm{~s}-2 \mathrm{p})-\mathrm{B}\end{array}$ & $\begin{array}{l}-\mathrm{C} \text { (main chain), }-\mathrm{C}_{6} \mathrm{H}_{5} \\
-\mathrm{C}_{6} \mathrm{H}_{5} \\
-\mathrm{C}_{6} \mathrm{H}_{5},-\mathrm{C} \text { (main chain) }\end{array}$ \\
\hline $\begin{array}{c}10.0 \\
(3.5-12)^{\mathrm{a}}\end{array}$ & $\begin{array}{c}(15.42 ; 15.27 \\
15.11 ; 14.81) \\
\text { many adjacent levels }\end{array}$ & $\begin{array}{l}\mathrm{C} 2 \mathrm{p} \\
\mathrm{C} 2 \mathrm{p}\end{array}$ & $\begin{array}{l}\mathrm{p} \sigma(\mathrm{C} 2 \mathrm{p}-\mathrm{H} 1 \mathrm{~s})-\mathrm{B} \\
\mathrm{p} \sigma(\mathrm{C} 2 \mathrm{p}-\mathrm{H} 1 \mathrm{~s})-\mathrm{B}\end{array}$ & $\begin{array}{l}-\mathrm{C} \text { (main chain), }-\mathrm{C}_{6} \mathrm{H}_{5} \\
-\mathrm{C}_{6} \mathrm{H}_{5},-\mathrm{C} \text { (main chain) }\end{array}$ \\
\hline & $\begin{array}{c}(16.09 ; 15.96 ; 15.77) \\
14.6 \sim 13.7 \\
(13.4 \sim 8.9)\end{array}$ & $\begin{array}{r}\mathrm{C} 2 \mathrm{p} \\
\mathrm{C} 2 \mathrm{p} \\
\mathrm{C} 2 \mathrm{p} \\
\mathrm{C} 2 \mathrm{p}\end{array}$ & $\begin{array}{l}\mathrm{p} \sigma(\mathrm{C} 2 \mathrm{p}-\mathrm{H} 1 \mathrm{~s})-\mathrm{B} \\
\mathrm{p} \sigma(\mathrm{C} 2 \mathrm{p}-\mathrm{H} 1 \mathrm{~s})-\mathrm{B} \\
\mathrm{p} \sigma(\mathrm{C} 2 \mathrm{p}-\mathrm{H} 1 \mathrm{~s})-\mathrm{B} \\
\mathrm{p} \sigma(\mathrm{C} 2 \mathrm{p}-\mathrm{H} 1 \mathrm{~s})-\mathrm{B} \\
\mathrm{p} \pi_{\mathrm{p}}(\mathrm{C} 2 \mathrm{p}-2 \mathrm{p})-\mathrm{B}\end{array}$ & $\begin{array}{l}-\mathrm{C}_{6} \mathrm{H}_{5},-\mathrm{C} \text { (main chain) } \\
-\mathrm{C}_{6} \mathrm{H}_{5},-\mathrm{C} \text { (main chain) } \\
-\mathrm{C}_{6} \mathrm{H}_{5},-\mathrm{C} \text { (main chain); } \\
\left.-\mathrm{C}_{6} \mathrm{H}_{5},-\mathrm{C} \text { (main chain) }\right\}\end{array}$ \\
\hline
\end{tabular}

${ }^{a}$ shows the peak range. ${ }^{\mathrm{b}} \pi_{\mathrm{p}}$ indicates the pseudo $\pi$ orbitals of the $\mathrm{CH}_{2}$ groups. B and NB mean bonding and non bonding, respectively. $(\mathrm{C} 2 \mathrm{~s}-2 \mathrm{~s}),(\mathrm{C} 2 \mathrm{~s}-2 \mathrm{p})$ mean $(\mathrm{C} 2 \mathrm{~s}-\mathrm{C} 2 \mathrm{~s}),(\mathrm{C} 2 \mathrm{~s}-2 \mathrm{p})$, respectively. 
0.26 for syndiotactic, heterotactic, and isotactic isomers, respectively. In Figures 3(b) and (c), we obtained similar calculated patterns for the isotactic and atactic types, as indicated in the previous work. ${ }^{14}$ The simulated patterns seem to correspond to the spectra for the isotactic PMMA, while the patterns could not reflect the ob- served difference between the peak and shoulder-curve around $14 \mathrm{eV}$ for isotactic and atactic types, respectively.

In Figures 4(a) and (b), the simulated spectra in the range of $0-40 \mathrm{eV}$ using isotactic and syndiotactic model trimers show good accordance with observed ones of isotactic and atactic PMMA, respectively, except for the

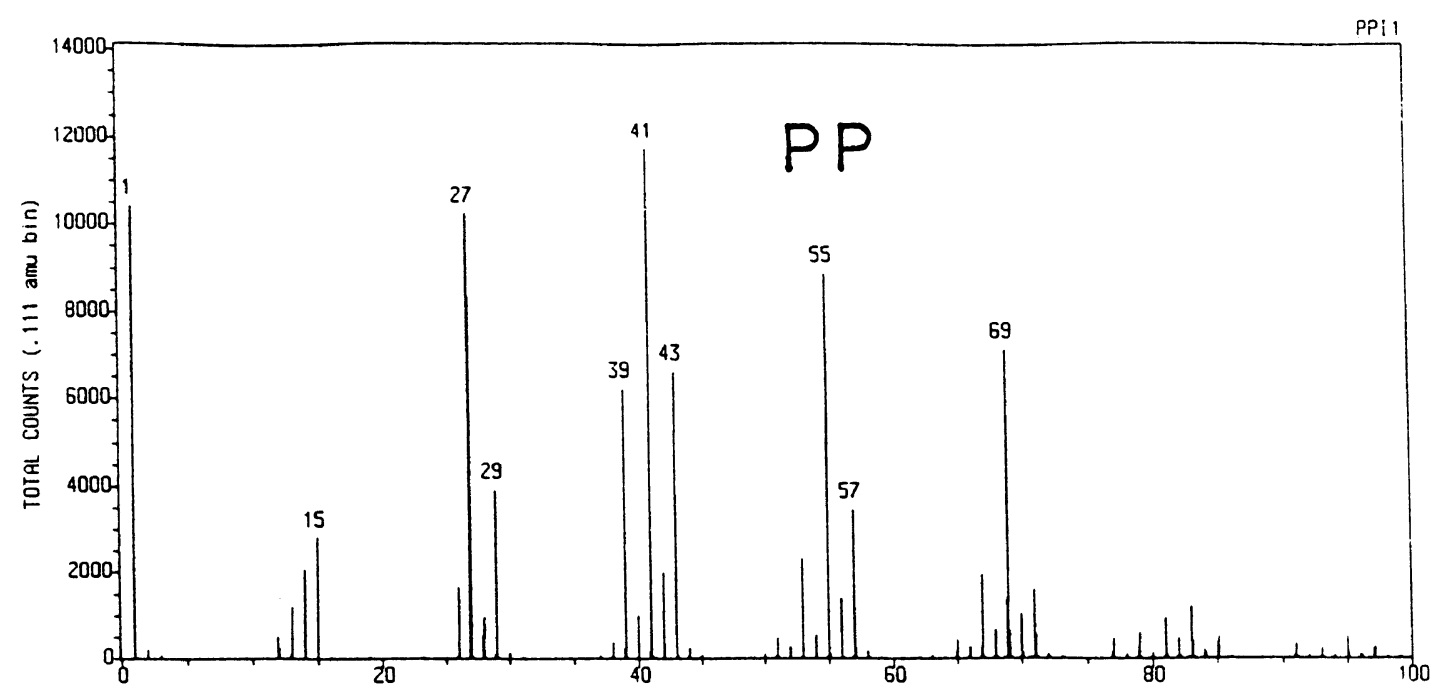

(a)

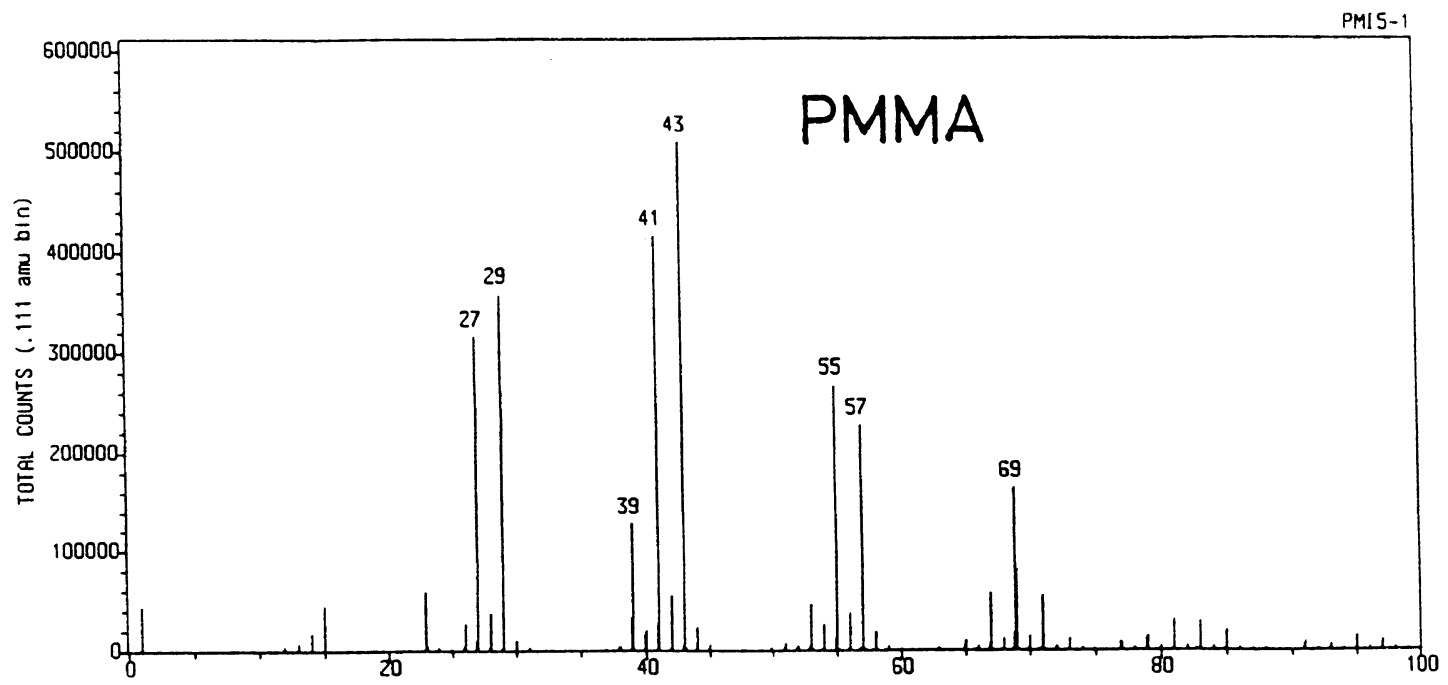

(b)

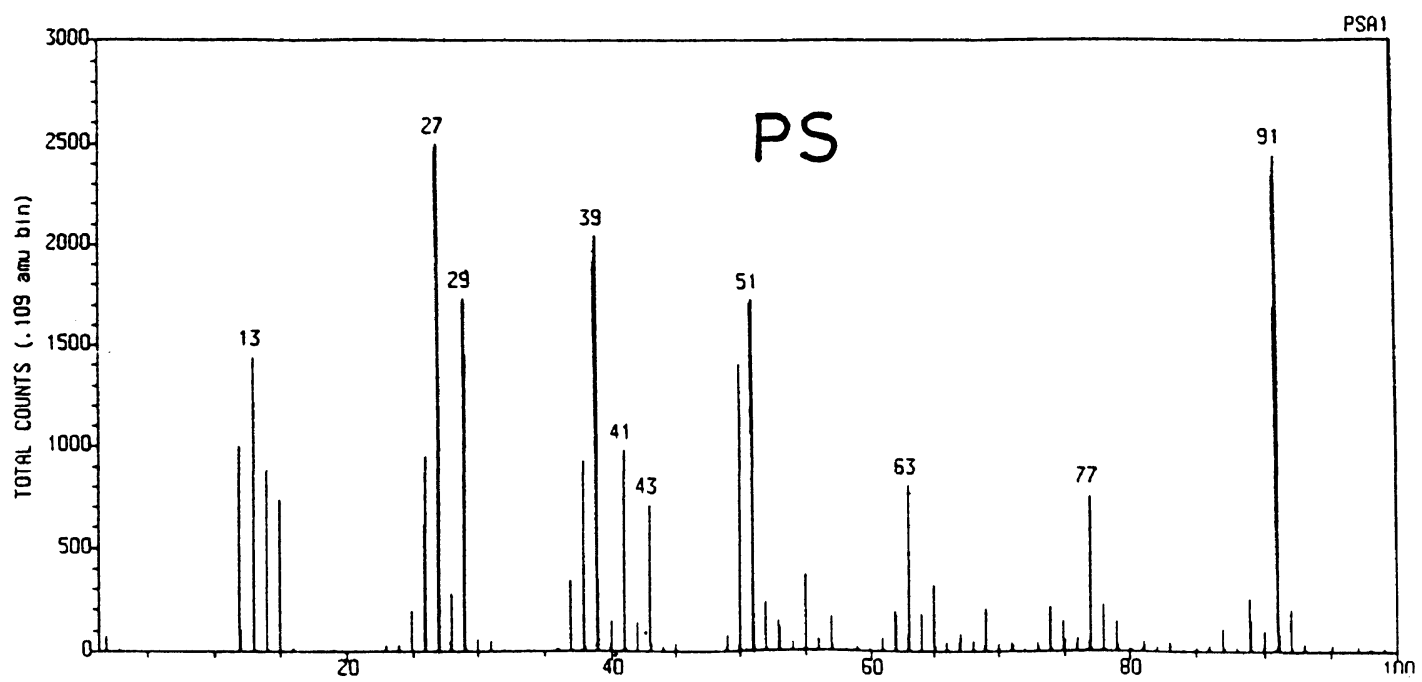

(c)

Figure 6. TOF-SIMS spectra for isotactic (a) PP, (b) PMMA, and (c) PS in the mass range of $0-100$ amu. 
Table II. Structure, dipole moment, heat of formation, and total energy of ion fragments in positive SIMS spectra of polypropylene

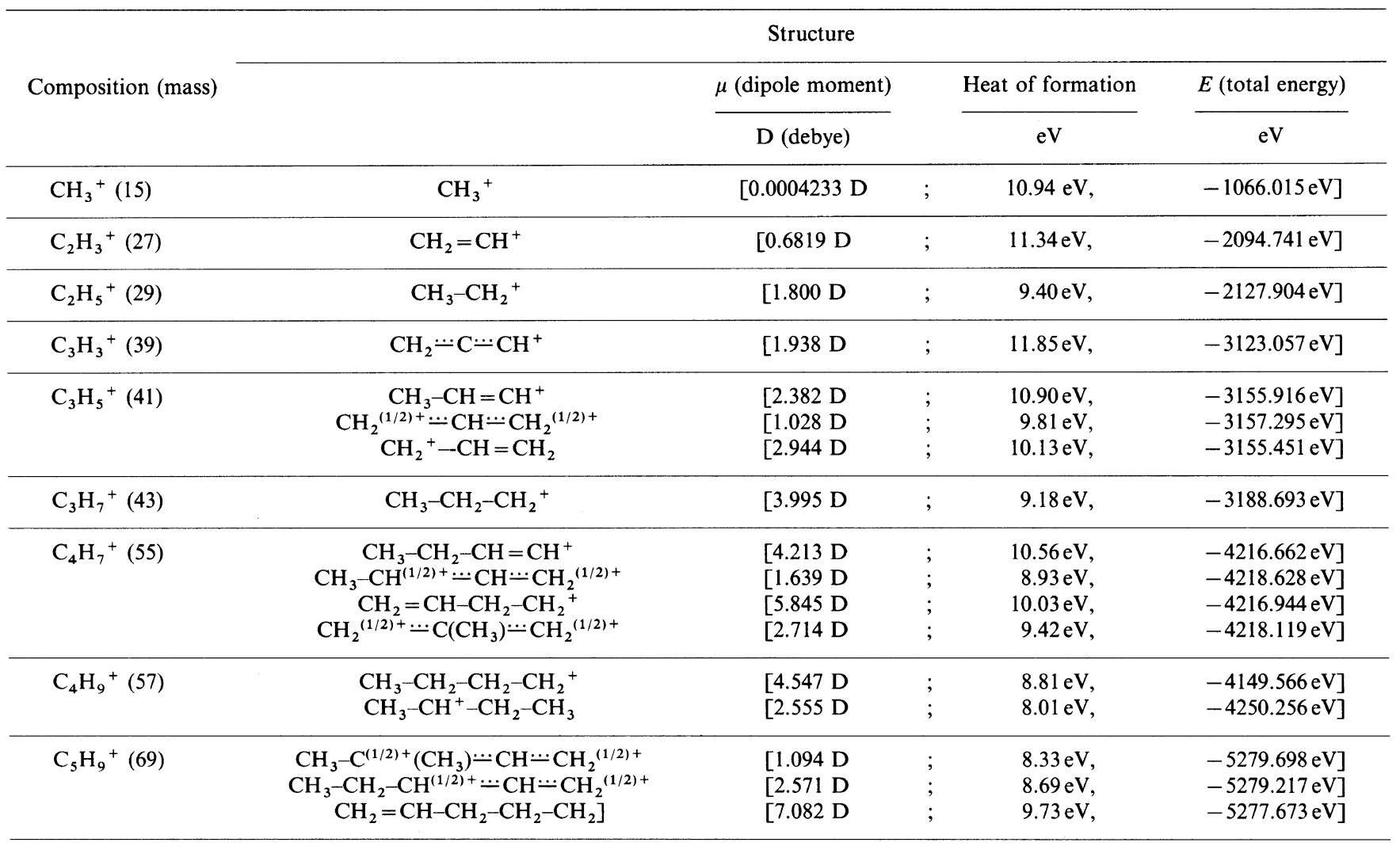

Table III. Structure, dipole moment, heat of formation, and total energy of ion fragments in positive SIMS spectra of polymethyl methacrylate

\begin{tabular}{|c|c|c|c|c|c|}
\hline \multirow{3}{*}{ Composition (mass) } & \multicolumn{5}{|c|}{ Structure } \\
\hline & & $\mu$ (dipole moment) & & Heat of formation & $E$ (total energy) \\
\hline & & D (debye) & & $\mathrm{eV}$ & $\mathrm{eV}$ \\
\hline $\mathrm{C}_{2} \mathrm{H}_{3}{ }^{+}(27)$ & $\mathrm{CH}_{2}=\mathrm{CH}^{+}$ & {$[0.6819 \mathrm{D}$} & ; & $11.34 \mathrm{eV}$ & $-2094.741 \mathrm{eV}]$ \\
\hline $\mathrm{C}_{2} \mathrm{H}_{5}{ }^{+}(29)$ & $\mathrm{CH}_{3}-\mathrm{CH}_{2}^{+}$ & {$[1.800 \mathrm{D}$} & ; & $9.40 \mathrm{eV}$ & $-2127.904 \mathrm{eV}]$ \\
\hline $\mathrm{C}_{3} \mathrm{H}_{3}{ }^{+}(39)$ & $\mathrm{CH}_{2} \stackrel{\cdots}{ } \cong \mathrm{CH}^{+}$ & {$[1.938 \mathrm{D}$} & ; & $11.85 \mathrm{eV}$ & $-3123.057 \mathrm{eV}]$ \\
\hline $\mathrm{C}_{3} \mathrm{H}_{5}{ }^{+}(41)$ & $\begin{array}{c}\mathrm{CH}_{3}-\mathrm{CH}=\mathrm{CH}^{+} \\
\mathrm{CH}_{2}{ }^{(1 / 2)+}+\cdots \mathrm{CH}-\mathrm{CH}_{2}^{(1 / 2)+} \\
\mathrm{CH}_{2}{ }^{+}-\mathrm{CH}=\mathrm{CH}_{2}\end{array}$ & $\begin{array}{l}{[2.382 \mathrm{D}} \\
{[1.028 \mathrm{D}} \\
{[2.944 \mathrm{D}}\end{array}$ & ; & $\begin{array}{l}10.90 \mathrm{eV} \\
9.81 \mathrm{eV} \\
10.13 \mathrm{eV}\end{array}$ & $\begin{array}{l}-3155.916 \mathrm{eV}] \\
-3157.295 \mathrm{eV}] \\
-3155.451 \mathrm{eV}]\end{array}$ \\
\hline $\mathrm{C}_{3} \mathrm{H}_{7}^{+}(43)$ & $\mathrm{CH}_{3}-\mathrm{CH}_{2}-\mathrm{CH}_{2}^{+}$ & {$[3.995 \mathrm{D}$} & ; & $9.18 \mathrm{eV}$ & $-3188.693 \mathrm{eV}]$ \\
\hline $\mathrm{C}_{4} \mathrm{H}_{7}{ }^{+}(55)$ & $\begin{array}{c}\mathrm{CH}_{3}-\mathrm{CH}_{2}-\mathrm{CH}=\mathrm{CH}^{+} \\
\mathrm{CH}_{3}-\mathrm{CH}^{(1 / 2)+}-\mathrm{CH}-\mathrm{CH} \mathrm{CH}_{2}^{(1 / 2)+} \\
\mathrm{CH}_{2}=\mathrm{CH}-\mathrm{CH}_{2}-\mathrm{CH}_{2}^{+} \\
\mathrm{CH}_{2}{ }^{(1 / 2)+}=\mathrm{C}\left(\mathrm{CH}_{3}\right)-\mathrm{CH}_{2}^{(1 / 2)+}\end{array}$ & $\begin{array}{l}{[4.213 \mathrm{D}} \\
{[1.639 \mathrm{D}} \\
{[5.845 \mathrm{D}} \\
{[2.714 \mathrm{D}}\end{array}$ & $\begin{array}{l}; \\
; \\
;\end{array}$ & $\begin{array}{r}10.56 \mathrm{eV} \\
8.93 \mathrm{eV} \\
10.03 \mathrm{eV} \\
9.42 \mathrm{eV}\end{array}$ & $\begin{array}{l}-4216.662 \mathrm{eV}] \\
-4218.628 \mathrm{eV}] \\
-4216.944 \mathrm{eV}] \\
-4218.119 \mathrm{eV}]\end{array}$ \\
\hline $\mathrm{C}_{4} \mathrm{H}_{9}{ }^{+}(57)$ & $\begin{array}{c}\mathrm{CH}_{3}-\mathrm{CH}_{2}-\mathrm{CH}_{2}-\mathrm{CH}_{2}^{+} \\
\mathrm{CH}_{3}-\mathrm{CH}^{+}-\mathrm{CH}_{2}-\mathrm{CH}_{3}\end{array}$ & $\begin{array}{l}{[4.547 \mathrm{D}} \\
{[2.555 \mathrm{D}}\end{array}$ & ; & $\begin{array}{l}8.81 \mathrm{eV} \\
8.01 \mathrm{eV}\end{array}$ & $\begin{array}{l}-4149.566 \mathrm{eV}] \\
-4250.256 \mathrm{eV}]\end{array}$ \\
\hline $\mathrm{C}_{5} \mathrm{H}_{9}{ }^{+}(69)$ & $\begin{array}{c}\mathrm{CH}_{3}-\mathrm{C}^{(1 / 2)+}\left(\mathrm{CH}_{3}\right) \cdots \mathrm{CH}-\mathrm{CH}_{2}^{(1 / 2)+} \\
\mathrm{CH}_{3}-\mathrm{CH}_{2}-\mathrm{CH}^{(1 / 2)+}-\mathrm{CH}-\mathrm{CH}_{2}^{(1 / 2)+} \\
\mathrm{CH}_{2}=\mathrm{CH}-\mathrm{CH}_{2}-\mathrm{CH}_{2}-\mathrm{CH}_{2}^{+}\end{array}$ & $\begin{array}{l}{[1.094 \mathrm{D}} \\
{[2.571 \mathrm{D}} \\
{[7.082 \mathrm{D}}\end{array}$ & ; & $\begin{array}{l}8.33 \mathrm{eV} \\
8.69 \mathrm{eV} \\
9.73 \mathrm{eV}\end{array}$ & $\begin{array}{l}-5279.698 \mathrm{eV}] \\
-5279.217 \mathrm{eV}] \\
-5277.673 \mathrm{eV}]\end{array}$ \\
\hline $\mathrm{C}_{4} \mathrm{H}_{5} \mathrm{O}^{+}(69)$ & $\begin{array}{c}\mathrm{CH}_{3}-\mathrm{C}\left(\mathrm{CH}_{2}\right)-\mathrm{C}^{+} \cdots \mathrm{O} \\
\mathrm{CH}_{3}-\mathrm{CH}=\mathrm{CH}-\mathrm{C}^{+} \rightleftharpoons \mathrm{O}\end{array}$ & $\begin{array}{l}{[2.877 \mathrm{D}} \\
{[2.282 \mathrm{D}}\end{array}$ & ; & $\begin{array}{l}7.70 \mathrm{eV} \\
7.36 \mathrm{eV}\end{array}$ & $\begin{array}{l}-6220.682 \mathrm{eV}] \\
-6220.985 \mathrm{eV}]\end{array}$ \\
\hline
\end{tabular}


observed shoulder-curve around $14 \mathrm{eV}$ for atactic types.

In the case of PS polymer, there were no characteristic difference of the observed spectra between the isotactic and atactic types (Figures 5(a) and (b)). The intense peaks at around $17 \mathrm{eV}$ are determined by $\mathrm{s} \sigma(\mathrm{C} 2 \mathrm{~s}-\mathrm{C} 2 \mathrm{~s})$ bonding orbitals of phenyl rings. The peaks at around 20.0 and $13.5 \mathrm{eV}$ correspond to the similar spectra in $\mathrm{s} \sigma(\mathrm{C} 2 \mathrm{~s}-\mathrm{C} 2 \mathrm{~s})$ and $\mathrm{p} \sigma(\mathrm{C} 2 \mathrm{~s}-\mathrm{C} 2 \mathrm{p})$ bondings of the main chain carbons, respectively, for PE and PP polymers. Table I shows the orbital characters of the PS polymer. The WD was estimated to be 5.5, 3.5, and 5.0 for PP, PMMA, and PS, respectively.

For these polymers, the spectra appeared to show good agreement with the observed ones when we used a Gaussian linewidth of $0.10 \mathrm{I}_{\mathrm{k}}$ for trimer, as proposed for simulating the valence XPS by taking account of the lifetime broadening by the hole filling of 2 s energy levels by 2 p electrons. ${ }^{17-19}$

\section{Spectral Analysis of Three Polymers in TOF-SIMS}

In Figure 6(a) - (c), we obtained positive-ion fragment spectra of PP, PMMA, and PS in the mass range of $0-100 \mathrm{amu}$. The fragment spectra seem to be quite simple. We, then, tried to predict where the scisson of the polymers occur on sputtering, although the emission process of secondary ions, atoms or molecules on sputtering is very complicated.
Let us consider a simplified process related to the emission of a fragment ion from solid polymer surface. When polymer sample is bombarded by source ions of a few ten keV kinetic energy, an impact cascade and an excited area are created around the point of primary particle impact through energy and momentum transfer from the bombarding particle to the solid polymer. Fragment ions are then formed by dissociation of sputtered neutral molecular species. The surface fragment ions are thus emitted, if a sufficient amount of energy is transfered.

We can discuss the dissociation of the neutral molecule species as the scission of polymer-bonds from the estimated values of the bond-orders of the model 5- or 3-mers by a semiempirical MO calculations using AM1 program (Figure 1). For hydrocarbons of PP and PS polymers, the scission of the bonds between carbon and carbons can occur in any carbon-carbon bonds, since the bond-orders except for phenyl rings were obtained as similar values of $0.97-0.99$. In the case of PMMA, the bonds between the main chain and carbonyl carbons may be scissile, when we consider the bond-orders of $0.90-0.91$ less than $0.95-0.99$ for other $\mathrm{O}-\mathrm{C}$ and $\mathrm{C}-\mathrm{C}$ chemical bonds.

We will, here, give reasonable structural formulas of each positive-ion fragment of the polymers in TOF SIMS by $a b$ initio calculations using HONDO7 program,

Table IV. Structure, dipole moment, heat of formation, and total energy of ion fragments in positive SIMS spectra of polystyrene

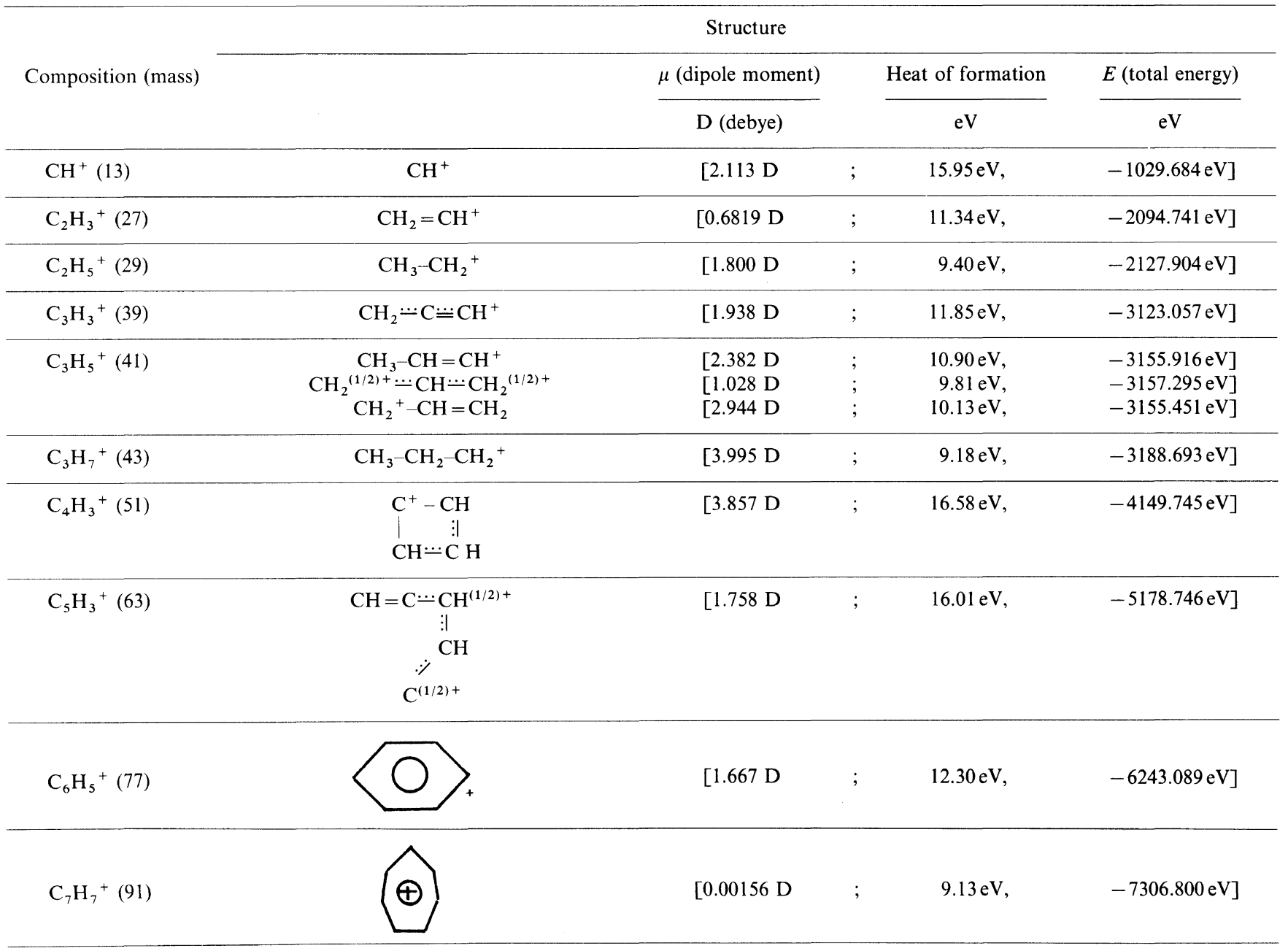


although the formulas of positive-ion fragments were empirically written by organic chemists. In Tables II-IV, we showed the probable structural formulas, dipole moments, heat of formation and total energies of the fragments for PP, PMMA, and PS polymers. For example, in the tables, the reasonable structural formulas of $\mathrm{C}_{3} \mathrm{H}_{5}{ }^{+}$fragment were determined as $\mathrm{CH}_{2}{ }^{(1 / 2)}+\ldots \mathrm{CH}-$ $\cdots \mathrm{CH}_{2}{ }^{(1 / 2)+}$ and $\mathrm{CH}_{2}{ }^{+}-\mathrm{CH}=\mathrm{CH}_{2}$ from the ab initio calculations, though organic chemists gave the formula of the fragment as $\mathrm{CH}_{3}-\mathrm{C}^{+}=\mathrm{CH}_{2}$. For the fragment of $\mathrm{C}_{5} \mathrm{H}_{3}{ }^{+}$of PS polymer, it can be seen that the fragment is a bent structure of $\mathrm{CH}=\mathrm{C} \cdots \mathrm{CH}^{(1 / 2)+}-\mathrm{CH} \cdots \mathrm{C}^{(1 / 2)+}$, since there is no five-member-ring because of a unstable structure (Table IV).

\section{Analysis of Tacticity of PMMA in the High Mass Range}

We obtained similar secondary positive-ion mass spectra for atactic and isotactic PMMA between 0-2000 amu (Figure 7$)$. In the figure, silver cations $\left(\mathrm{Ag}^{+}\right.$(107 or
109), ${ }^{109} \mathrm{Ag}^{107} \mathrm{Ag}^{+}$(216), ${ }^{109} \mathrm{Ag}^{107} \mathrm{Ag}_{2}{ }^{+}$(323)) were observed, since there was a monolayer or less and island structure of PMMA on the silver foils. At around 1000 amu, we can see the different mass spectra for both atactic and isotactic types. Figure 8 shows the distinct spectra for PMMA of different stereoregularity in the range of $800-1300 \mathrm{amu}$.

In the case of the atactic spectra, we obtained $\mathrm{C}_{l} \mathrm{H}_{m} \mathrm{O}_{n} \mathrm{Ag}_{5}{ }^{+}(m>l>n)$ and $\mathrm{C}_{l^{\prime}} \mathrm{H}_{m^{\prime}} \mathrm{O}_{n^{\prime}} \mathrm{Ag}_{2}{ }^{+}\left(m^{\prime}>l^{\prime}>n^{\prime}\right)$ from the spectral mass analysis, while the patterns for the isotactic type showed $\mathrm{C}_{l 1} \mathrm{H}_{m 1} \mathrm{O}_{n 1} \mathrm{Ag}_{2}{ }^{+}(m 1>l 1>n 1)$, $\mathrm{C}_{41} \mathrm{H}_{53} \mathrm{O}_{27}{ }^{109} \mathrm{Ag}^{+}$and $\mathrm{C}_{l^{\prime \prime}} \mathrm{H}_{m^{\prime \prime}} \mathrm{O}_{n^{\prime \prime}} \mathrm{Ag}_{3}{ }^{+}\left(m^{\prime \prime}>l^{\prime \prime}>n^{\prime \prime}\right)$ mass units (see Table $\mathrm{V}$ ). Our results are fairly different from repeat patterns of an integral number of monomer units plus $\mathrm{C}_{2} \mathrm{H}_{6} \mathrm{O}$ all cationized with silver $(n \mathrm{M}+$ $\mathrm{C}_{2} \mathrm{H}_{6} \mathrm{O}+\mathrm{Ag}^{+}$) as obtained by Zimmerman and Hercules. ${ }^{8}$

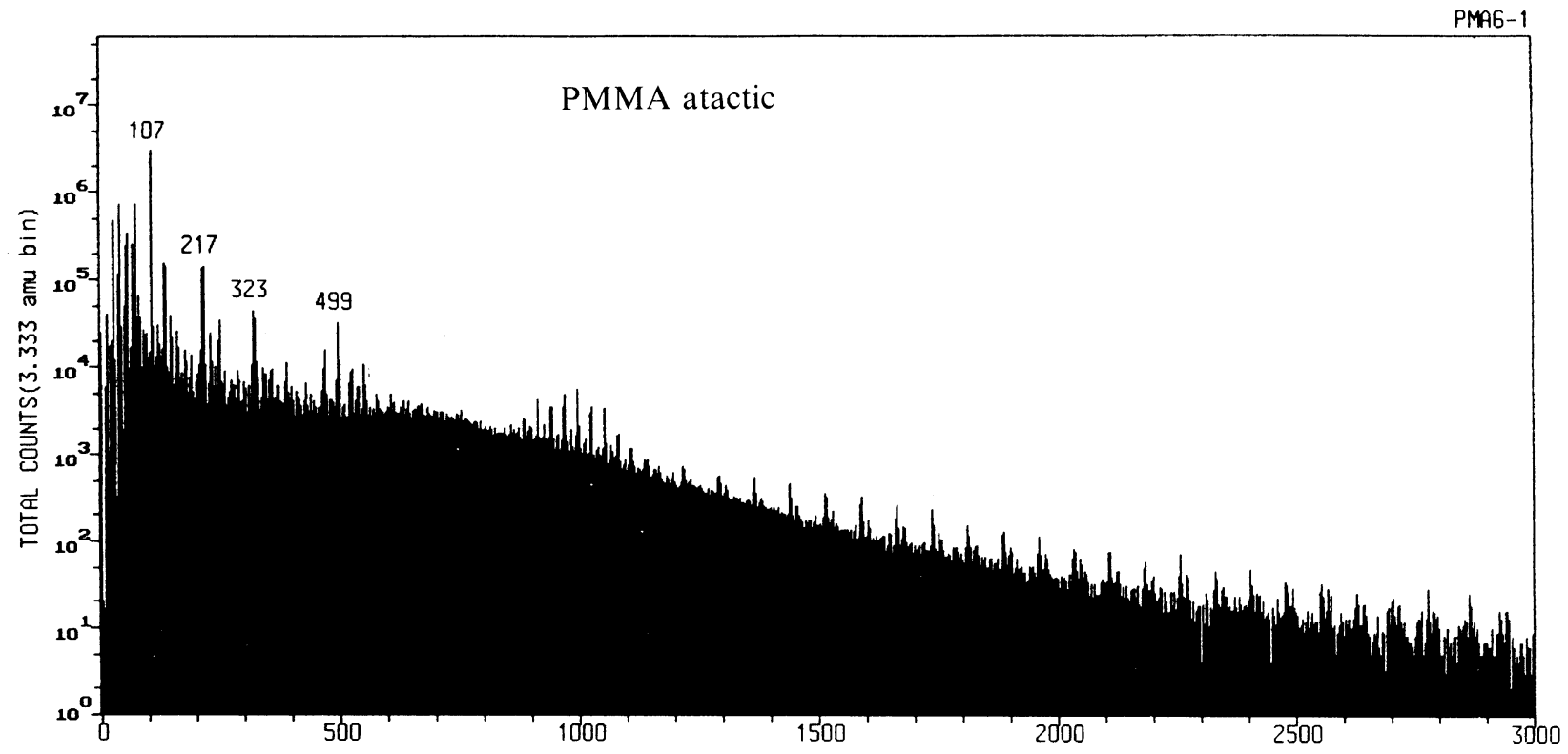

(a)

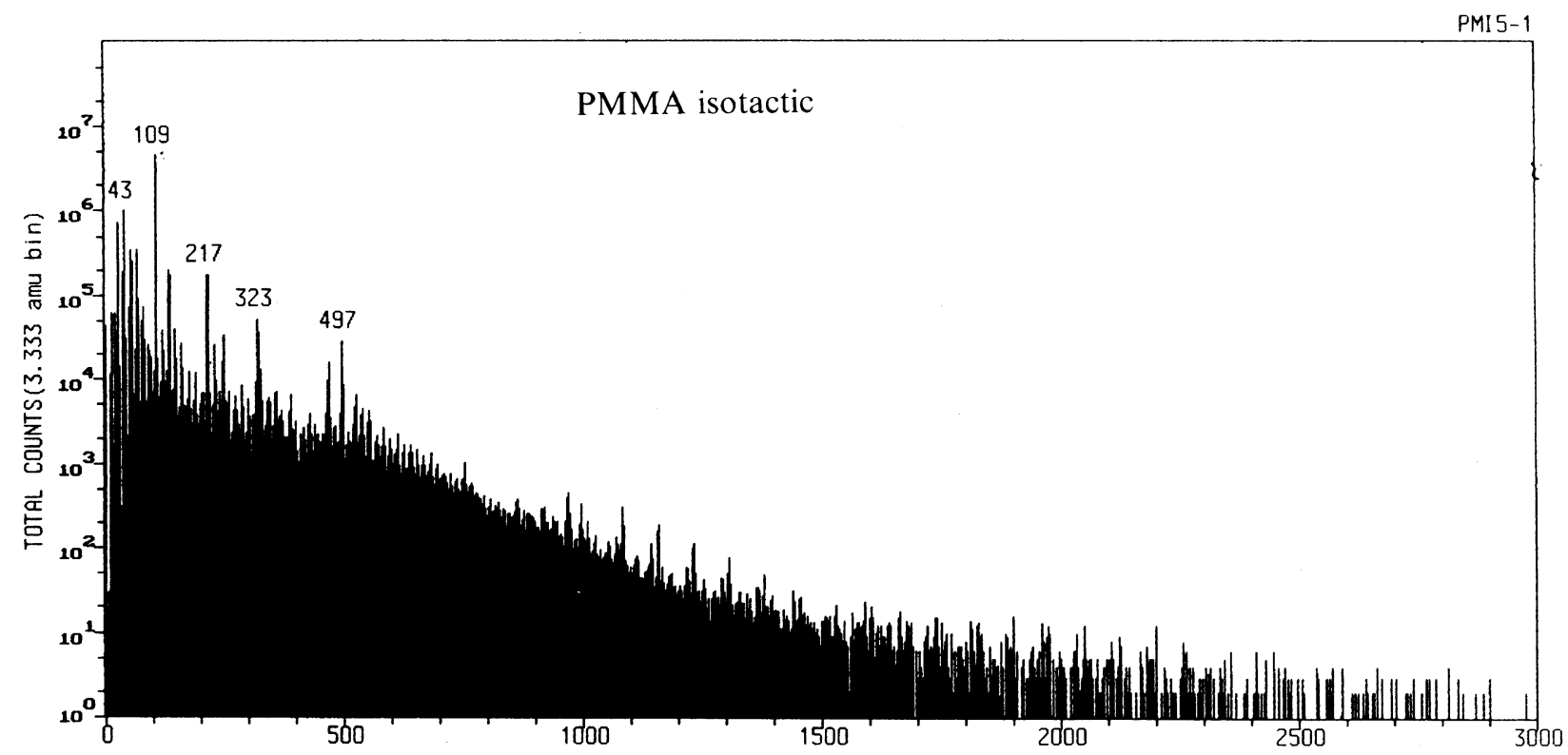

(b)

Figure 7. TOF-SIMS spectra for (a) atactic and (b) isotactic PMMA in the mass range of $0-2000 \mathrm{amu}$. 

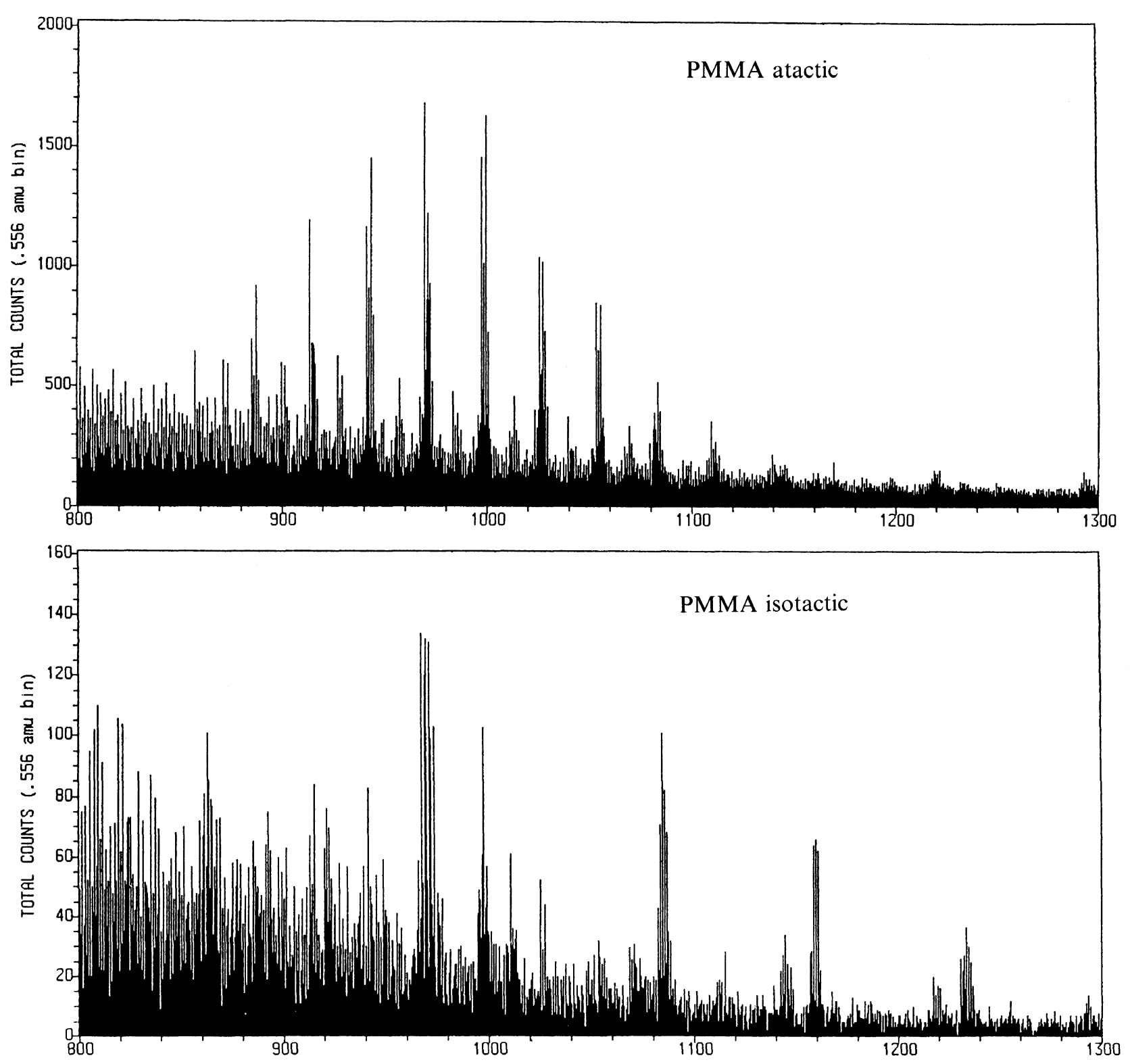

Figure 8. TOF-SIMS spectra for (top) atactic and (bottom) isotactic PMMA in the mass range of $800-1200 \mathrm{amu}$.

\section{CONCLUSION}

We have analyzed the spectra of PP, PMMA, and PS polymers in TOF-SIMS and valence $\mathrm{X}$-ray photoelectron spectroscopy by MO calculations using model oligomers.

(1) For TOF SIMS, we could predict where the scission of polymers can occur on sputtering, due to the bond-orders of the oligomers by a semiempirical MO calculations. In the case of PMMA, the bonds between the main chain and carbonyl carbons can be scissible, when we consider the bond-orders of $0.90-0.91$ less than $0.95-0.99$ for other $\mathrm{O}-\mathrm{C}$ and $\mathrm{C}-\mathrm{C}$ bonds.
(2) We have gave reasonable structural formulas of each positive-ion fragment of the polymers in TOF-SIMS by ab initio calculations using HONDO7 program. For the fragment of $\mathrm{C}_{5} \mathrm{H}_{3}{ }^{+}$of PS polymer, the fragment is

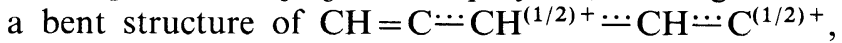
since there is no five-member-ring because of an unstable structure.

(3) The valence XPS of the polymers were simulated by a semiempirical HAM/3 MO method using the trimer model molecules. The theoretical spectra showed good agreement with the observed spectra of polymers between $0-40 \mathrm{eV}$. 
Table V. Mass numbers, relative intensities, and the formulas for the clusters in TOF-SIMS for atactic and isotactic PMMA in the high mass range

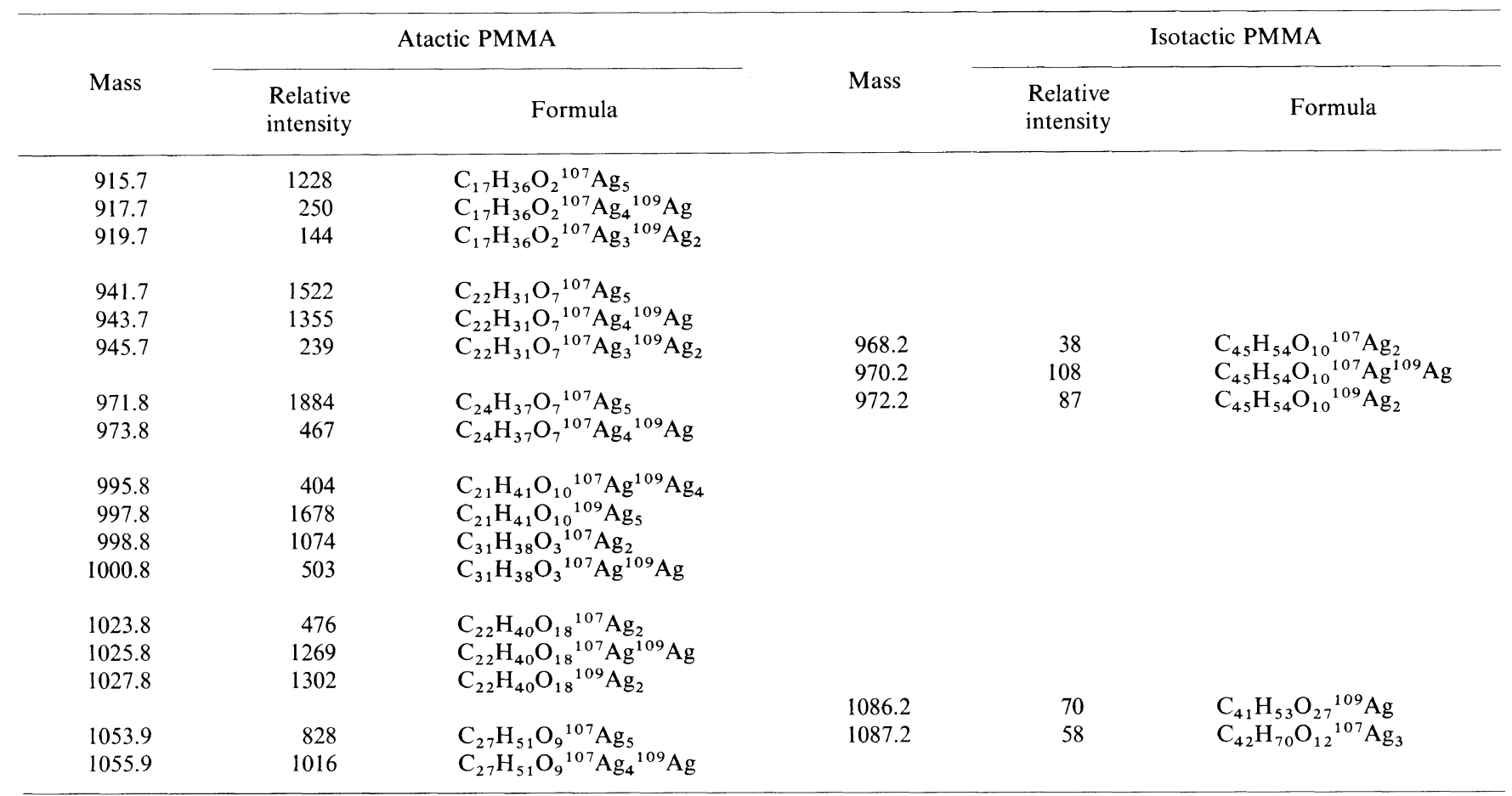

\section{REFERENCES}

1. P. A. Zimmerman and D. M. Hercules, Anal. Chem., 65, 983 (1993).

2. D. Briggs, in "Practical Surface Analysis," Vol. 2, Ion and Neutral Spectroscopy, D. Briggs and M. P. Seah Ed., Wiley, Chichester, 1992, p 367.

3. I. V. Bletsos, D. M. Hercules, D. vanLeyen, A. Benninghoven, C. G. Karakatsanis, and J. N. Rieck, Macromolecules, 23, 4157 (1990).

4. I. V. Bletsos, D. M. Hercules, D. vanLeyen, A. Benninghoven, C. G. Karakatsanis, and J. N. Rieck, Anal. Chem., 61, 2142 (1989).

5. A. Benninghoven, F. G. Rudenauer, and H. W. Werner, in "Secondary Ion Mass Spectrometry," P. J. Elving and J. D. Winefordner Ed., Wiely, Chichester, 1987.

6. J. J. P. Stewart, J. Composite Chem., 10, 289 (1989).

7. M. S. Dupuis, J. D. Watts, H. G. Villar, and G. J. B. Hurst, HONDO, Version 7; Scientific and Engineering Computations Dept. 48B, IBM Corp., New York, N.Y., 1978, p 1240.

8. P. A. Zimmerman and D. M. Hercules, Appl. Spectrosc., 48, 620 (1994).

9. P. Boulanger, R. Lazzaroni, J. J. Verbist, and J. Delhalle, Chem. Phys. Lett., 129, 275 (1986).

10. P. Boulanger, J. Riga, J. J. Verbist, and J. Delhalle, Macromolecules, 22, 173 (1989).

11. J. Delhalle, S. Delhalle, and J. Riga, J. Chem. Soc., Faraday Trans., 2, 503 (1987).

12. J. Delhalle, R. Montigny, C. Demanet, and J. M. Andre, Theor. Chem. Acta, 50, 343 (1979).

13. J. Delhalle, J. Riga, J. P. Denis, M. Deleuze, and M. Dosiere, Chem. Phys. Lett., 210, 21 (1993).
14. K. Endo, N. Kobayashi, M. Aida, and C. Inoue, J. Phys. Chem. Solids, 54, 887 (1993).

15. K. Endo, C. Inoue, N. Kobayashi, T. Higashioji, and $\mathbf{H}$. Nakatsuji, Bull. Chem. Soc. Jpn., 66, 3241 (1993).

16. K. Endo, C. Inoue, N. Kobayashi, and M. Aida, J. Phys. Chem. Solids, 55, 471 (1994).

17. C. Inoue, Y. Kaneda, M. Aida, and K. Endo, Polym. J., 27, 300 (1995).

18. K. Endo, Y. Kaneda, M. Aida, and D. P. Chong, J. Phys. Chem. Solids, 56, 1131 (1995).

19. K. Endo, C. Inoue, Y. Kaneda, M. Aida, N. Kobayashi, and D. P. Chong, Bull. Chem. Soc. Jpn., 68, 528 (1995).

20. M. Aida, Y. Kaneda, N. Kobayashi, K. Endo, and D. P. Chong, Bull. Chem. Soc. Jpn., 67, 2972 (1994).

21. L. Åsbrink, C. Fridh, and E. Lindholm, Chem. Phys. Lett., 52, 63 (1977): Quantum Chemistry Program Exchange, 12, No. 398 (1980).

22. L. Åsbrink, C. Fridh, and E. Lindholm, Chem. Phys. Lett., 52, 69 (1977).

23. E. Lindholm and L. Åsbrink, "Molecular Orbitals and Their Energies, Studied by the Semiempirical HAM Method,' SpringerVerlag, Berlin, 1985.

24. J. C. Slater, Advan. Quantum Chem., 6, 1 (1972).

25. U. Gelius and K. Siegbahn, Faraday Discus. Chem. Soc., 54, 257 (1972): U. Gelius, J. Electron. Spectrosc. Relat. Phenom., 5, 985 (1974).

26. D. P. Chong, Can. J. Chem., 63, 2007 (1985).

27. V. I. Nefedov, N. P. Sergushin, I. M. Band, and M. B. Trzhaskovskaya, J. Electron. Spectrosc. Relat. Phenom., 2, 383 (1973). 